\section{SCIDoc Publishers}

International Journal of Anesthesiology \& Research (IJAR)

ISSN 2332-2780

\title{
Anaesthesia - Related Fears - A Cross - Sectional Survey Among the Portuguese Population
}

\author{
Research Article
}

Pereira $\mathrm{C}^{* *}$, Sobreira Fernandes $\mathrm{D}^{1}$, Carmezim Mota $\mathrm{A}^{1}$, Gonçalves $\mathrm{G}^{1}$, Pinho $\mathrm{S}^{1}$, Araújo $\mathrm{M}^{1}$, Pereira $\mathrm{F}^{1}$, Saraiva $\mathrm{A}^{1}$, Paiva $\mathrm{M}^{1}$, Nunes $\mathrm{CS}^{2}$, Cavaleiro $\mathrm{C}^{1}$, Machado $\mathrm{H}^{1}$

${ }^{1}$ Serviço de Anestesiologia, Centro Hospitalar do Porto.

${ }^{2}$ Universidade Aberta, Department of Sciences and Technology, Delegação do Porto, Portugal

\section{Abstract}

Introduction: Patients experience preoperative anxiety. The objective of this study was to assess patients' fears concerning anaesthesia and evaluate possible associations with sociodemographic background and previous anaesthesia.

Methods: A survey was filled preoperatively, for 6 months, including anaesthesia-related fears, sociodemographic data, previous anaesthesia and surgery, current surgical and anaesthetic procedure, and preferred anaesthesia technique. Descriptive statistics, principal component analysis, Chi-square test, t-test and ANOVA were used for statistical analysis.

Results: 153 questionnaires were collected. The mean age was 58 years, $61.4 \%$ were female and 59.5\% employed. $47.1 \%$ had an anaesthesia consultation before. $49.7 \%$ were ASA II. $78.4 \%$ had been submitted to surgery before, $81.7 \%$ to anaesthesia and $14.5 \%$ had regional anaesthesia. In 73.5\% general anaesthesia preferred. Half of patients with previous regional anaesthesia favoured this technique. The most relevant fears were "being paralysed because of anaesthesia", "not waking up" and "waking up during surgery". The least relevant were "fasting incapacity", "having nightmares" and "speaking of personal matters". A statistically significant relation was observed between the fear of "feeling pain after surgery" and having a previous anaesthetic experience. Female and unemployed patients were more concerned with general complications, while male patients gave more importance to awareness and paralysis.

Conclusion: Paralysis after anaesthesia, intraoperative awareness and death were the main concerns of our inquiries.

Keywords: Anaesthesia; Population; Physician Service.

\section{Introduction}

Patients frequently experience fear and anxiety during the preoperative period, related to surgical and anaesthetic factors [1-4]. Perioperative anxiety can be associated with insufficient information provided to patients concerning anaesthesia, contributing to inadequate preconceived ideas about its role [5-7]. Previous studies have identified an association between patients' fears and their sociodemographic background and previous exposure to anaesthesia [8-10].

Perioperative anxiety is associated with the increase of intraoperative anaesthetic drug requirements and increased sympathetic response (tachycardia, arrhythmia and hypertension) [11]. It has also been associated with postoperative morbidity, such as increased pain scores, nausea and vomiting, and delayed hospital discharge $[2,4,11-14]$.

The preoperative anaesthetic consultation and visit are unique opportunities to clarify any fear the patient might have and contribute to the relief of their anxiety [1, 15-17]. Simple measures such as explaining a patient's disease and proposed surgical and anaesthetic procedure can be enough to relieve he patient's anxiety [18].

The primary endpoint of this cross-sectional study was to assess the patients' fears concerning anaesthesia among the Portuguese population and the secondary endpoint was to evaluate if the identified fears are associated with the patients' sociodemograph-

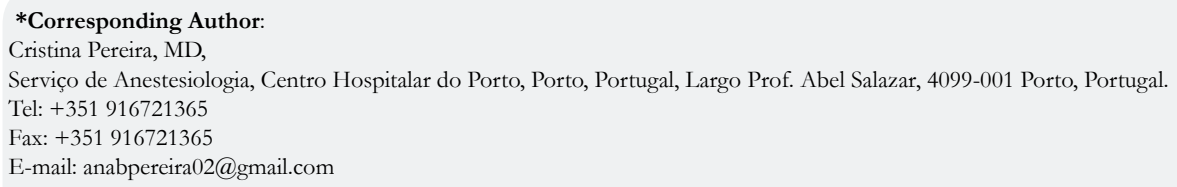

Citation: Pereira C, Sobreira Fernandes D, Carmezim Mota A, Gonçalves G, Pinho S, Araújo M, et al., Anaesthesia - Related Fears - A Cross - Sectional Survey Among the Portuguese Population. Int J Anesth Res. 2018;6(1):494-499. doi: http://dx.doi.org/10.19070/2332-2780-18000100

Copyright: Pereira $\mathbf{C}^{\circ}$ 2018. This is an open-access article distributed under the terms of the Creative Commons Attribution License, which permits unrestricted use, distribution and reproduction in any medium, provided the original author and source are credited. 
ic background and previous exposure to anaesthesia.

\section{Methods}

This study was conducted in a Portuguese tertiary hospital, after the approval of the Ethics Committee: Comissão de Ética para a Saúde (Largo Professor Abel Salazar, 4099-001 Porto), Ref.: 204.150 (105-DEFI/135-CES).

The authors elaborated a survey after reviewing of the available publications related to anaesthetic fears $[2,6]$. Questionnaires were filled during the preoperative anaesthesia consultation and preoperative anaesthetic visit, after obtaining patients' written informed consent. Data collection took place during 6 months. Non-obstetric patients scheduled for elective inpatient surgery, aged 18 years and above were included in the study. Exclusion criteria included patient's refusal, cognitive disability and patients scheduled for Neurosurgery or Cardiothoracic surgery.

The questionnaire was divided in two sections. The first comprised a total of 17 anaesthesia-related fears, assessed by the patients with a Likert scale from 1 (no concern at all) to 5 (extreme concern) (Table 1).

The second section of the questionnaire combined sociodemographic data (age, gender, level of education and employment status) and previous exposure to anaesthesia and surgery. The proposed surgical and anaesthetic procedure, as well as its duration, were also taken into account. The final multiple-choice question assessed their preferred Anaesthesia technique, if they were given a choice (General - unconscious, regional - conscious but painfree, or No preference).

Descriptive statistics was performed to identify the main anaesthetic fears and to characterize the population's sociodemographic data. Then, principal component analysis was used to detect similarities in the patients' fears and to determine if there were different components in the evaluated fears. Chi-square test (for categorical variables), t-test and ANOVA (for continuous variables) were used to analyse the relationship between the demographic data and the patients' fears. Statistical significance was considered for a $\mathrm{p}$-value $<0.05$. Data was analysed using SPSS (Statistical Package of Social Science) version 22.0.

\section{Results}

A total of 153 questionnaires were collected, 19\% ( $n=29)$ during the preoperative anaesthesia consultation and $81 \%(n=124)$ during de preoperative anaesthetic visit (Table 2). The patients' mean age was 58 years old (standard deviation 14.6; minimum 19, maximum 89 years), 61.4\% ( $\mathrm{n}=94)$ were female and $59.5 \%$ $(n=91)$ were employed. More than half of the patients had six or less years of education. Only $47.1 \%(n=72)$ had an anaesthesia consultation before being admitted for the scheduled surgery.

$44.1 \%(n=63)$ were scheduled for urologic surgery followed by $25.9 \%(n=37)$ for general surgery. $49.7 \%(n=76)$ were classified as American Society of Anaesthesia Physical Status (ASA PS) II and $80.9 \%(\mathrm{n}=114)$ were proposed for general anaesthesia. $23.8 \%$ $(\mathrm{n}=34)$ of the procedures had a predicted duration of less than 1 hour, $54.5 \%(n=78)$ between 1 and 3 hours, and 21.7\% $(n=31)$ of more than 3 hours. $78.4 \%(n=120)$ of the patients had already been submitted to surgery and $81.7 \%(\mathrm{n}=125)$ to anaesthesia. $14,5 \%(n=22)$ had had regional anaesthesia before. A total of $73.5 \%(n=111)$ and $20.5 \%(n=31)$ of patients designated general anaesthesia and regional anaesthesia as their preferred type of anaesthesia, respectively. $6.0 \%(n=9)$ mentioned no preference for any specific type of anaesthesia.

The preferred anaesthesia technique was associated with past regional anaesthesia $(\mathrm{p}<0.001)$. Half of patients with this previous experience favoured a regional Anaesthesia technique, against only $15 \%$ of patients who had never experienced regional anaesthesia.

Table 1. Anaesthetic Fears Evaluated in the Questionnaire.

\begin{tabular}{|l|}
\hline 1. Fasting incapacity \\
\hline 2. Having nightmares \\
\hline 3. Feeling pain during surgery \\
\hline 4. Fear of the unknown \\
\hline 5. Fear of needles \\
\hline 6. Staying unconscious \\
\hline 7. Involuntarily speaking of personal matters \\
\hline 8. Waking up during surgery \\
\hline 9. Feeling pain after surgery \\
\hline 10. Anaesthesia affecting thoughts \\
\hline 11. Not waking up after anaesthesia \\
\hline 12. Nausea and vomiting after surgery \\
\hline 13. Paralysis because of anaesthesia \\
\hline 14. Being mistreated by the Anaesthesiologist \\
\hline 15. Anaesthesiologist not being present during the procedure \\
\hline 16. Qualifications of the Anaesthesiologist to anaesthetize \\
\hline 17. Qualifications of the Surgeon to operate \\
\hline
\end{tabular}


The anaesthesia related fears with higher frequency of Likert 5 answers were "being paralysed because of anaesthesia" (35.6\%, $\mathrm{n}=47$, with 21 missing), "not waking up" (32.7\%, n=49, with 3 missing) and "waking up during surgery" (with $23.0 \%, \mathrm{n}=25$, with 1 missing) (Graph 1). The anaesthesia related fears with higher frequency of Likert 1 answers were "fasting incapacity" (85.5\%, $\mathrm{n}=130$, with 1 missing), "having nightmares" $(82.9 \%, \mathrm{n}=126$, with 1 missing) and "speaking of personal matters" $(80.4 \%, n=119$, with 5 missing) (Graph 1). No relationship between the above described fears and the analysed socio-demographic variables, previous anaesthesia or surgery was observed.

A statistically significant relation was observed between the fear of "feeling pain after surgery" and previous anaesthetic experience $(p=0.039)$, when the other anaesthetic fears were analysed. $28.1 \%$ with previous anaesthesia experience were very concerned (Likert 5) with "feeling pain after surgery" against $46.4 \%$ without previous anaesthesia.

When principal component analysis was performed, four different components were identified. The Kaiser-Meyer-Olkin (KMO) measure showed a good adequacy (0.817), and the Bartlett's test of sphericity was significant ( $\mathrm{p}<0.001)$. The four identified components could be named as: Component 1 "Most known complications", Component 2 "Anaesthetist Behaviour", Component 3 "Awareness and Paralysis due to Anaesthesia", and Component 4 "Least relevant fears".

Component 1 aggregated questions 3 to 6,9 to 12,16 and 17 . These questions relate to the most well known surgical procedures' complications, and incorporate the fear of under qualifications of the clinicians (which could also impact on the incidence of overall complications). Component 2 aggregates questions 14 and 15, which are the ones related to the anaesthetist's attitudes or behaviour towards the patient. Component 3 aggregates questions 8 and 13, which are the fear of awareness and paralysis due to anaesthesia. Component 4 aggregates questions 1, 2 and 7, which were the questions to which the patients gave the lowest Likert scale.

The identified 4 components were analysed with respect to their relationship with the different sociodemographic characteristics of patients.

Female and unemployed patients were more concerned with the

Table 2. Demographic Data and Proposed Procedures: number (\%) or median (IQR).

\begin{tabular}{|l|l|}
\hline Demographic Data and Proposed Procedures & n (\%) or Median (IQR) \\
\hline Age & $59(19-89)$ \\
\hline Gender & \\
\hline Male & $59(38,6)$ \\
\hline Female & $94(61,4)$ \\
\hline Education Level & \\
\hline No education & $4(2,6)$ \\
\hline First cycle (4 years) & $59(38,6)$ \\
\hline Second cycle (6 years) & $20(13,1)$ \\
\hline Middle School (9 years) & $30(19,6)$ \\
\hline High School (12 years) & $27(17,6)$ \\
\hline University & $12(7,8)$ \\
\hline Post-Graduation & $1(0,7)$ \\
\hline Employment Status & \\
\hline Employed & $91(74,5)$ \\
\hline Unemployed & $23(15,0)$ \\
\hline Retired & $39(25,0)$ \\
\hline ASA Score & \\
\hline I & $18(12,6)$ \\
\hline II & $76(53,1)$ \\
\hline III & $45(31,5)$ \\
\hline IV & $4(2,8)$ \\
\hline Surgery & \\
\hline Urology & $63(44,1)$ \\
\hline General Surgery & $37(25,9)$ \\
\hline Orthopaedic & $15(10,5)$ \\
\hline Head and Neck & $24(16,8)$ \\
\hline Other & $4(2,8)$ \\
\hline Proposed Anaesthesia & \\
\hline General & $114(80,9)$ \\
\hline Regional & $12(8,5)$ \\
\hline Combined & $15(10,6)$ \\
\hline
\end{tabular}


Figure 1. Answers concerning possible fears due to Anaesthesia (1. Fasting incapacity, 2. Having nightmares, 3. Feeling pain during surgery, 4. Fear of the unknown, 5. Fear of needles, 6. Staying unconscious, 7. Involuntarily speaking of personal matters, 8 . Waking up during surgery, 9. Feeling pain after surgery, 10. Anaesthesia affecting thoughts, 11. Not waking up after anaesthesia, 12. Nausea and vomiting after surgery, 13. Paralysis because of anaesthesia, 14. Being mistreated by the Anaesthesiologist, 15. Anaesthesiologist not being present during the procedure, 16. Qualifications of the Anaesthesiologist to anaesthetize, 17. Qualifications of the Surgeon to operate)

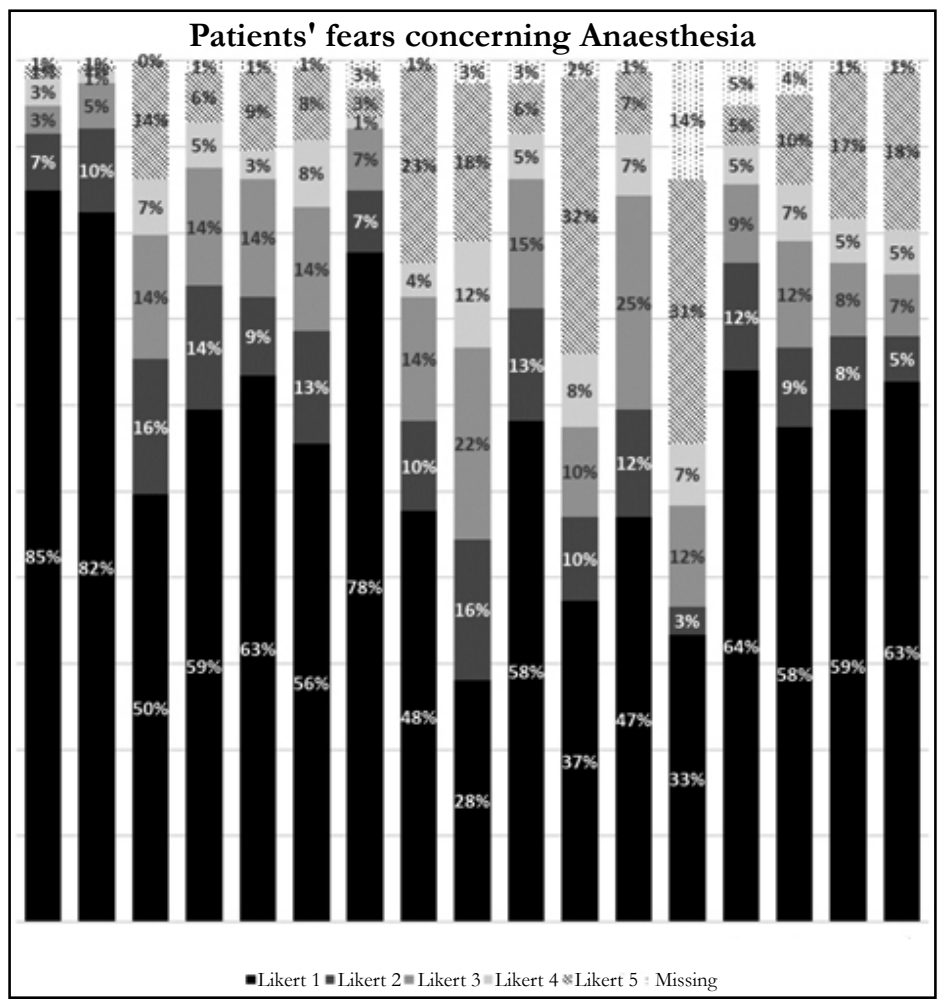

fears grouped in Component 1, the "Most Known Complications" ( $p=0.0004$ and $p=0.024$ respectively). Age, level of education and patient's previous exposure to anaesthesia and surgery were not associated with this group of fears.

None of the considered socio-demographic variables were associated with the fears grouped in Component 2 and 4, "Anaesthetist Behaviour" and "Least relevant fears" respectively. Previous anaesthesia or surgical exposure was also not associated with Component 2. However, patients without previous anaesthesia experience gave more importance to Component 4 ( $\mathrm{p}=0.0042)$.

The gender was the only variable associated with the fears grouped in Component 3, "Awareness and Paralysis due to anaesthesia", that is, males were more concerned with this fear $(p=0.014)$.

\section{Discussion}

Patients' anaesthetic fears are a common problem of anaesthetic care [6]. A majority of patients ( $81 \%$ to $88,9 \%)$ affirm they are anxious about anaesthesia during the preoperative period $[2,10]$. A pre-anaesthetic interview with the patient decreases preoperative anxiety, although a small number of studies have tried to identify patients' greatest concerns [6].

Nevertheless, apart from gaining knowledge about how informed patients were, their attitudes and concerns, this survey identified important key issues, which needed to be addressed. Even though this study might not be representative of the whole Portuguese population, and cannot therefore be generalized, it is a valuable source of information to better understand the patients from our hospital and to act upon their misconceptions and fears during the preoperative visit.

The most important fears identified in this study were: "being paralysed because of anaesthesia", "not waking up" and "waking up during surgery". In a study by Mavridou et al, in a Greek hospital, the fears of postoperative pain, death, nausea, needles and drains were the ones patients most mentioned [2]. Shevde et al., found that when questioned about their fears, most patients from an American hospital feared not waking up and experiencing intraoperative or postoperative pain or some type of postoperative disability [6]. Ruhaiyem et al., in Saudi Arabia, found that disclosing private matters while under anaesthesia, anaesthesia failure, or waking up during surgery were the most relevant fears [10]. These studies suggest that patients' fears are different between countries, especially between cultures.

In our principal component analysis, awareness and paralysis (questions 8 and 13) were aggregated in the same component 3. This result might be explained by the fact that, despite their rarity, paralysis is a devastating iatrogenic complication and awareness is an extremely stressful event and, in this sense, well known and feared by the population.

Female gender and unemployment status were associated with higher Likert scores regarding the fears of component 1 (surgical procedure complications). Some studies have shown that women seem to express more fear and preoperative anxiety than men [2, 10]. We suggest as hypothesis that this result might be attributed 
to the fact that generally men are more reluctant to admit their fears $[2,6]$. However, there is an association between male gender and a higher concern for the fears aggregated in component 3, consciousness and paralysis due to anaesthesia.

The least relevant fears (component 4) included "fasting incapacity", "having nightmares" and "speaking of personal matters". Patients without a previous anaesthesia experience gave more importance to these fears. Given the evolution of anaesthesia, and the decreasing number of these complications, patients with a previous anaesthesia experience probably had the opportunity to clarify these fears with an anaesthetist, which might be a possible explanation for this result.

In our population, general anaesthesia is largely preferred to regional techniques, but having had a previous regional anaesthesia significantly increases the probability of selecting these in the future. Shevde et al., found similar results in their study, since $69 \%$ of their patients also preferred general anaesthesia, but tended to prefer the type of anaesthesia they had had in the past [6]. This leads us to think that giving better and more adequate information about the different anaesthesia techniques, explaining what is to be expected, might increase their adherence to what is more suitable for them.

The fact that only $47.1 \%$ of the patients had an anaesthesia consultation before being admitted for the scheduled surgery could be explained by the large percentage of patients classified as ASA I and II, which, in our centre, aren't usually prioritized for these consultations.

Some of the limitations of our study are related to the low gathered number of questionnaires that investigators could collect during the survey period. Because of the sample size, this data does not represent the population as a whole and some selection bias would inevitably have taken place when asking patients to participate in the survey [18]. Most of our surveys were applied during the preoperative anaesthetic visit, the day before surgery, which might contribute to the overestimation of the degree of fear they report due to the impending surgery.

The size and complexity of the survey, with a Likert scale of difficult understanding for some patients, specially accounting for the low education level of the studied sample, might have contributed to the missing data.

Since the surveys were filled by the authors, and not by the patients themselves, as a way of including analphabetic patients in the study, there might have been an interviewer bias.

The demographic differences we found in our population cannot obviously be modified; they can only be understood in order to attain some clues as to how to act and what to change in our practice. Meanwhile, the patients' concerns regarding paralyses due to anaesthesia, not waking up and awareness can be specifically addressed, but the information process should always be personalized. The information must be clear and should not increase the patients' preoperative anxiety [9].

In our survey, we observed that the anaesthesia fears are influenced by previous anaesthesia experience. The adequate information about unpleasant anaesthetic events is critical to clarify those fears. Working to improve the information we transmit to patients is the key to achieve better results in order to cope with anxiety, promoting a better perioperative care. The preoperative anaesthesia evaluation is the moment to approach this issue.

\section{Conclusion}

Paralysis after anaesthesia, intraoperative awareness and death were the main identified anaesthetic concerns of our inquiries. Paralysis and awareness are more important for the male gender. Female and unemployed patients are more concerned about surgical complications. Patients without a previous anaesthesia experience expressed more fear related to fasting, nightmares and speaking of personal matters.

The access to a preoperative anaesthetic interview should be available to all patients as a way of giving the adequate information to our patients.

Efforts to educate the general population on the anaesthesiologist's role in perioperative care should improve patient confidence and reduce their preoperative anxiety. Making this information available for the whole population, by means of leaflets, websites and public activities should be the goal [6]. Recognizing our patients' main fears and misconceptions is the first step to reach the general population and to better inform them about Anaesthesiology, improving our service to the community.

\section{References}

[1]. Davidson S, McKendrick D, French T. Preassessment clinic interview and patient anxiety. Saudi J Anaesth. 2016 Oct-Dec;10(4):402-408. PubMed PMID: 27833482; PubMed Central PMCID: PMC5044723.

[2]. Mavridou P, Dimitriou V, Manataki A, Arnaoutoglou E, Papadopoulos G. Patient's anxiety and fear of anesthesia: effect of gender, age, education, and previous experience of anesthesia. A survey of 400 patients. 2013 Feb;27(1):104-8. doi: 10.1007/s00540-012-1460-0. PubMed PMID: 22864564.

[3]. Valenzuela Millán J, Barrera Serrano JR, Ornelas Aguirre JM. Anxiety in preoperative anesthetic procedures.Cir Cir. 2010 Mar-Apr;78(2):147-51. PubMed PMID: 20478116.

[4]. Kain ZN, Wang SM, Mayes LC, Caramico LA, Hofstadter MB. Distress during the induction of anesthesia and postoperative behavioral outcomes. Anesth Analg. 1999 May;88(5):1042-7. PubMed PMID: 10320165.

[5]. Leite F, Silva LM, Biancolin SE, Dias A, Castiglia YM. Patient perceptions about anesthesia and anesthesiologists before and after surgical procedures. Sao Paulo Med J. 2011;129(4):224-9. PubMed PMID: 21971897.

[6]. Shevde K, Panagopoulos G. A survey of 800 patients' knowledge, attitudes, and concerns regarding anesthesia. Anesth Analg. 1991 Aug;73(2):190-8. PubMed PMID: 1854034

[7]. Klafta JM, Roizen MF. Current understanding of patients' attitudes toward and preparation for anesthesia: a review. Anesth Analg. 1996 Dec;83(6):1314-21. PubMed PMID: 8942605.

[8]. Yilmaz M, Sezer H, Gürler H, Bekar M. Predictors of preoperative anxiety in surgical inpatients. J Clin Nurs. 2012 Apr;21(7-8):956-64. doi: 10.1111/j.1365-2702.2011.03799.x. PubMed PMID: 21812848.

[9]. Mavridou P, Dimitriou V, Papadopoulou M, Manataki A, Arnaoutoglou E, Papadopoulos G. Effect of previous anesthesia experience on patients' knowledge and desire for information about anesthesia and the anesthesiologist: a 500 patients' survey from Greece. Acta Anaesthesiol Belg. 2012;63(2):63-8. PubMed PMID: 23136806.

[10]. Ruhaiyem ME, Alshehri AA, Saade M, Shoabi TA, Zahoor H, Tawfeeq NA. Fear of going under general anesthesia: A cross sectional study. Saudi J Anaesth. 2016 Jul-Sep;10(3):317-21. doi: 10.4103/1658-354X.179094. PubMed PMID: 27375388; PubMed Central PMCID: PMC4916817.

[11]. Maranets I, Kain ZN. Preoperative anxiety and intraoperative anesthetic requirements. Anesth Analg. 1999 Dec;89(6):1346-51. PubMed PMID: 10589606.

[12]. Williams JB, Alexander KP, Morin JF, Langlois Y, Noiseux N, Perrault LP, 
et al. Preoperative Anxiety as a Predictor of Mortality and Major Morbidity in Patients $>70$ Years of Age Undergoing Cardiac Surgery. Am J Cardiol. 2013 Jan 1;111(1):137-42. doi: 10.1016/j.amjcard.2012.08.060. PubMed PMID: 23245838 ; PubMed Central PMCID: PMC3677723.

[13]. Kalkman CJ, Visser K, Moen J, Bonsel GJ, Grobbee DE, Moons KG. Preoperative prediction of severe postoperative pain. Pain. 2003 Oct;105(3):41523. PubMed PMID: 14527702.

[14]. Van den Bosch JE, Moons KG, Bonsel GJ, Kalkman CJ. Does measurement of preoperative anxiety have added value for predicting postoperative nausea and vomiting?. Anesth Analg. 2005 May;100(5):1525-32. PubMed PMID: 15845719 .

[15]. Ribeiro CS, de Barros Mourão JI. Anesthesiologist: the patient's perception.
Braz J Anesthesiol. 2015 Nov;65(6):497-503.

[16]. Hocking G, Weightman WM, Smith C, Gibbs NM, Sherrard K. Measuring the quality of anaesthesia from a patient's perspective: development, validation, and implementation of a short questionnaire. Br J Anaesth. 2013 Dec;111(6):979-89. doi: 10.1093/bja/aet284. PubMed PMID: 23985532.

[17]. Matthey P, Finucane BT, Finegan BA. The attitude of the general public towards preoperative assessment and risks associated with general anesthesia. Can J Anaesth. 2001 Apr;48(4):333-9. PubMed PMID: 11339773.

[18]. Chew ST, Tan T, Tan SS, Ip-Yam PC. A survey of patients' knowledge of anaesthesia and perioperative care. Singapore Med J. 1998 Sep;39(9):399-402. PubMed PMID: 9885718. 